\title{
Art and Education in Leisure Institutions: Making a Case for Research
}

\section{Lara M. Lackey}

Is this a topic that you have created or did they give you a topic? Well, I don't think you're going to get a very long thesis out of that!

(Comments of a senior-aged woman, a tole painter working at a community recreation center. upon hearing my explanation of my dissertation research.)

In common-sense terms "education" occurs in schools, "leisure" is the opposite of work, and "art" fits within domains of play or recreation rather than work or education (Lackey, 1994). These interrelated conventional understandings are reflected and perpetuated by the ways in which art education has been institutionalized in Western society, remaining a marginal school subject but embraced readily as part of non-school learning environments. The research in which I am currently submerged offers an opportunity for art educators to question these ideas, as perhaps they already have. It also poses a challenge, however, to take art education practices that occur at non-school sites more seriously, and to consider what we might be able to learn from them.

My research uses ethnographic methods to explore how art activities "fit" within the contexts of two community recreation centers in Greater Vancouver. Community recreation centers are familiar institutions throughout North America. In my city they are municipally funded, and their brochure covers commonly feature some child or adult engaged in a seasonal sport or physical activity--tennis, soccer, ice hockey, etc.. Indeed the field of recreation has its roots in physical education. Interestingly, however, a substantial portion of the content in these brochures may include that which is categorized as art or craft programming. Art activities are provided for all ages and within a range of structures--as part of special events, as one portion of a more general program of children's "play" or child care, or as the exclusive focus of a course. Recently there has been a campaign to increase the emphasis on recreational arts programming in my region, and to find more ways to include art and artists in these centers. Much of my own background has involved work in community-based art education, and I have long been

\footnotetext{
${ }^{1}$ An expanded version of many of the arguments in this paper are of fered in Lackey (1994).
} 
curious to see if I could understand just how art activity was framed within these kinds of contexts, dominated as they are by sport, fitness, and a focus on the physical needs of the body as distinct from the mind.

There is a sense, however, in which the apparent triviality of such a study needs to be dealt with at the outset, and an argument needs to be made as to why it bears any relation to educational concerns. As noted, it is common to dismiss activity which occurs in non-formai settings as insignificant or not part of the realm of education. The fact that this activity occurs during what is labeled as "leisure" or "free time" suggests "play" or "non--work," somehow lacking in value, status, or importance. Ostensibly, my research is a case of "studying down." There are a number of good reasons why art educators need to pay attention to what happens in non--formal settings.

First, it is the case that non-tormal institutions and arts organizations increasingly view art education within their own mandates (Soren, 1993). Arguably their motives and purposes (overt or tacit) in providing art educational activities may differ from those of schools, but often the activities themselves--what participants actually experience--may closely mimic school practices. The prevalent availability of art educational activities outside of school is a characteristic that distinguishes art from core school subjects, and, although non-formal art education has been left relatively unexamined by researchers, there is evidence in our literature that it creates a tension for school art educators and may be viewed as threatening to democratic educational access or to the primacy of schools as sites for art education (Chapman, 1992; Fowler, 1984; Kimpton, 1984; Smith, 1980).

Second, the literatures of lifelong learning and adult education have encouraged us to reconceptualize what counts as education and to recognize that facilitated leaming occurs in a wide range of contexts. In addition, critical theorists have noted the relationships between sanctioned schooling/curricula and dominant powers in our society, pointing to the relatively arbitrary ways in which leaming experiences are selected for credentialing or not. (Ililich, 1971; Bowles \& Gintis, 1976; Apple, 1990; Apple, 1993). Other authors have urged us to consider both the possibilities that alternative sites offer for pursuing more democratic and egalitarian social agendas, and the common goals of "cultural workers" across a range of settings (Giroux, 1992; Trend 1992).

Changes in technology as well as our appearing to be on the verge of significant shifts in our economic and social organization--what Lyotard (1979/1984) calls our "postmodern condition"--suggest that educational 
structures will soon change and evolve as well. Already we are seeing the blurning of lines between formal and non-formal reaims.

One of the ways in which such changes occur is when school educators are urged to seek out relationships with non-school organizations in order to augment school art programs, and to enlist these alternative organizations as part of a broader art education network. Ironically, the common-sense assumptions surrounding notions of art and leisure, both linked to play and personal choice, may converge in ways which pose leisure institutions as somehow more "free" or more appropriate than schools for art education, a position that needs to be more closely examined. Rather, we are naive if we assume that any institutional context comes without ideological and structural parameters, complicated by complex issues of power. Where non-formal establishments engage in educational activity or form associations with schools, we need to understand and work to make explicit the contextual possibilities and constraints which necessarily frame the programming which is provided by such sites.

I view researching art activity in community recreation centers as relevant to education for all of these reasons. These sites are interesting, however, because they can be viewed as places where the ideologies of sport, recreation, and leisure converge with those of art and education. In addition, as these and similar organizations increasingly involve themselves in art educational practices, they solidify their own positions as art institutions, sites where forms of art knowledge are constructed and perpetuated. As such, they warrant the same kinds of critical analysis that has been applied to schools and other art educational contexts.

\section{About the Sites}

I have selected the two community recreation centers in which to conduct my work. One is situated in an area which has been described to me as generally lower income and highly "multicultural." For example, although the dominant social group in Vancouver is descended from Northern Europeans, an effect of British colonization, this community contains large populations of established and recent immigrants from Vietnam, China, and various countries in Southern Europe. In addition there is a prevalent First Nations presence in the area. I have been told that a number of youths who regularly attend the center and use its free "games room" have very troubled home lives. Many live in group homes or foster homes, and the center has special staff to counsel and work with these youth. This center is known for its strong martial arts program, although any kind of programming that costs 
money is difficult to implement because of the community's general inability to pay the fees.

The other center is situated on the west side of Vancouver in a relatively affluent section of town. This site is filled with pale-skinned peopie, and there is a strong British influence--it is common, for example, to hear British accents among adults who frequent the center. Here, the only noticeable non-Northern European presence is a number of Filipino women who are the nannies to the large number of preschool children in the area. In this case, in courses designed for parents and children to attend together, or where adults are invited to the presentation of a final performance, it is often the nanny who attends or participates in the parents' places. This center is known as a program "machine". People line up to get into programs on registration nights, and the community demand for programming is so high that the center often cannot keep up with it.

\section{Questions}

The overriding question with which I am concerned is, How does art programming "fit" within the contexts of these centers? Some of the more specific questions in which I am interested, however, are, How do administrators, instructors, participants, and parents experience and understand the purposes of art programming in these settings? How do these perspectives converge with or diverge from each other? How are notions such as art, artist, craft, recreation, education, and leisure constructed and acted upon in these settings? How do issues of socioeconomics, class, gender, and culture or ethnicity reveal themseives in these contexts? How do organizational culture and structure affect art programming in these settings? What formal and informal messages or assumptions do these institutions hold and disseminate about art programming within their frames: What possibilities and constraints for art educational activity might these sites afford?

\section{Methods}

I have been trying to gather relevant data to these questions through many hours of program observations and interviews with people who work in and use these sites. I will also be analyzing a range of documents produced in the settings, which I have been collecting over the past year. In addition ! have been using photography to document artistic products and the visual environments of the centers, realizing the futility of trying to "describe" visual artifacts in my written field notes and becoming alert to the informal messages of the institutions which can in part be found in the structure of the buildings 
and in the interior designs and visual displays. In addition I gradually recognized that I could not understand how "art" programming is positioned and conceptualized within these settings without also getting a sense of the centers as wholes, and how approaches to visual art may be compared and contrasted, for example, with other activities. In this sense, my observations and research experiences have touched on a wide range of activities outside the categories of visual art or craft.

\section{Emerging Themes}

Part of being an ethnographic researcher is learning to reflect on the assumptions with which you entered the setting and how your ideas have been altered, perhaps how you have been surprised, by contact with the site. While I am not ready to write "conclusions" for this study--which is still in progress--! can begin this process of reflection.

First, in terms of my overriding question about how "art" is seen to "fit" within these contexts, I think my assumption was that art might be perceived in a relatively cohesive or universal way in these institutions, and that it might be possible to state that perception in fairly succinct terms. In addition, I think that I assumed that it would be possible to find a great deal of what art educators might frame as uncritical practice, perhaps practice that promoted a notion of art activity as rather meaningless play. What troubles these assumptions is that art fits within these contexts in a wide variety of ways, according to the structure and perceived purposes of the programming within which it occurs, as well as the background and value of the people who instruct and administer it. Art projects I have observed, for example, included: egg carton "caterpillars" enhanced with pipe cleaners, feathers, glitter, and rolling plastic eyes created for the purpose of developing "gluing" skills; a collaborative mural produced to honor a multicultural community but which nevertheless was constrained and influenced by the ideological and structural frames of the social institution on which it emerged; oversized still life work in the "style" of Matisse; and clay tiles carved and stained with scenes of lake life, created by adults and children in the neighborhood as part of a project to celebrate and save a dying lake. (Later these tiles were sealed to the tops of the wooden tables in the center snack bar.) In other words I have found art education practice that is both as banal and as interesting as that which might be found in schools, permeated by the same kinds of social influences and artistic assumptions--art in the service of engendering technical skill; art as celebration; art as representation; art as emulation of historical work; art as a means of heightening awareness of social or political circumstances. In each case the practices are framed and negotiated within 
structures, values, and beliefs that form the parameters of the social institutions in which they were produced.

A second assumption I brought with me to my research was that I might find a fair amount of tension, in terms of how art was perceived. Between people who administered these centers and those who taught art courses in them. The administrators, almost without exception, have backgrounds in physical education and are often accomplished high-level athletes but have little or no experience in art; those who teach the art courses, however, at least those programs that focus exclusively on art, tend to be trained in an colleges. The assumption that there would be some differences in how the functions of art programming in these settings were understood by these two sets of people has proved to be at least partly correct, and can be addressed. The commonality between the two groups, however, is perhaps more interesting that their differences. What both groups seem to agree on is the possibility of the community center as a site for doing and learning all kinds of things, and the less-structured altemative such sites provide to schools, which both artists and administrators assume to be authoritarian and restrictive. Members of both groups, for example, told me that in choosing careers, they made deliberate decisions not to work in schools, in spite of an interest in working with people in learning environments.

Yet another misconception that I arrived with was that people in these settings would be able to articulate fairly clearly the ways in which they perceived distinctions between "education" and "recreation." I have been interested in how these terms are often used rather arbitrarily to categorize and bestow status on activities. In this study, however, I have found their meanings to be quite blurred and overlapping, and certainly not easy to define. It is often, however, people who teach art in these settings who perceive what they do as "education" rather than "recreation." For example, one woman told me quite adamantly that what she did was not recreation, but "education wrapped in fun."

issues related to socio-economics, class, and culture leap out of the data in this study, especially pertaining to questions like, Who has leisure? and Who has access to these programs? These facilities are, after all, posed as being available and welcoming to all, and as meeting community needs. Who can participate, who can volunteer their time, who can justify making art for art's sake rather than art perceived as functional, who can afford to pay as much for art supplies as one paid for the course fees, as well as the ways in which "needs" of each community are construed by those who design the 
programs in each setting, will undoubtedly surface as important in this study's findings.

Finally, there are issues emerging around how art and sport programming tend to divide along gender lines in these sites, and how that is reflected in the designed environments of the centers. The centers are physically buit around major facilities like ice rinks, gymnasiums, fitness centers, and racquetball courts which tend to be used by males, although not exclusively. The art programs, on the other hand, are primarily used by females and the art facilities, by contrast, are small, cluttered and shared by many "arts" activities as opposed to being designed and designated for one type of program.

\section{Summary}

In this paper I have taken literally the notion of providing a "working paper" in art education, one which reflects my emerging thoughts as ! progress in my research. Art educators need to pay closer attention to practice which occurs in non-school sites, and I point to some of the interesting questions that may be pursued in community settings, questions that are of interest to art educators working in a wide range of contexts.

\section{References}

Apple, M.W. (1990). Ideology and Curriculum (2nd Edition). London; Routledge \& Kegan Paul.

Apple, M.W. (1993). Official Knowledge: Democratic Education in a Conservative Age. New York/London: Routledge.

Bowles, S. \& Gintis, H. (1976). Schooling in Capitalist America: Educational Reform and the Contradictions of Economic Life. New York:Basic Books.

Chapman, L. (1992). Arts Education as a Political issue: The Federal Legacy. In R.A. Smith \& R. Berman (Eds.), Public Policy and the Aesthetic Interest: Critical Essays on Defining Cultural and Educational Relations (pp. 119-136). University of Illinois Press: Urbana/Chicago.

Fowler, C.B. (1984). Some Arts Educators see the Community as Competition: Who Owns Arts Education? Design for Arts in Education, 86(2), 4-7. 
Giroux, H.A. (1992). Border Crossings: Cultural Workers and the Politics of Education. New York:Routledge.

Illich, I. (1971) Deschooling Society. New York: Harper and Row.

Kimpton, J. (1984). Public Education and the Arts: Linked by Necessity. Design For Arts in Education, 8 6(2), 8-12.

Lackey, L. (1994). Art, Education, Work, and Leisure: Tangles in the Lifelong Learning Network. Journal of Social Theory in Art Education, 14, 148-169.

Lyotard, J. F. (1984). The Postmodern Condition: A Report on Knowledge (G. Bennington \& B. Massumi, Trans.). Minneapolis: University of Minneapolis. (Original work published 1979).

Soren, B. J. (1993). Nurturing mind, Spirit, and a Love of the Arts and Sciences: Schools and Cultural Organizations as Educators. Studies in Art Education, 34,(3), 149-157.

Trend, D. (1992). Cultural Pedagogy: Art/Education/Politics. Cultural Studies in Education and Culture Series, H. A. Giroux and P. Freire (Eds.). New York: Bergin \& Garvey. 